\title{
Restricted Movement of the Shoulder and Severe Pain: Separation of the Acromioclavicular Joint
}

\author{
(D) Ataman Köse, (D) Serkan Karakulak, (D) Gizem Yoğurtçu, (D) Seyran Bozkurt
}

Department of Emergency Medicine, Mersin University Faculty of Medicine, Mersin, Turkey

A 22-year-old male patient was admitted to the emergency room after falling on the left arm while playing football. On the examination, he has severe pain on the left arm and restricted to bring abduction. An anti-inflammatory analgesic drug was administered intramuscularly to the patient whose vital signs were stable at the time of admission. Then, the patient had a two-sided AP shoulder graphy. On the graphy, type III acromioclavicular joint (ACJ) dislocation was detected according to Rockwood classification on the left shoulder (Figure 1a,b). The patient was consulted in the orthopedics department. The patient had a shoulder tomography (Figure 2) and admitted to the orthopedic clinic. Surgical operation was performed by the orthopedic clinic (Figure 3). The patient was discharged without any problem after the operation.

We wanted to present a case of ACJ separation assessed as type III in the emergency department patient with shoulder motion restriction and severe pain. ACJ separation is a rare diagnosis in patients presenting with emergency services with limited shoulder movement and severe pain. The ACJ separation is an injury that accounts for approximately $12 \%$ of shoulder injuries in all populations. This rate can reach up to $50 \%$ in athletes (1). According to the Rockwood classification, there are six types of ACJ injuries. Type I, II, III is more common and, type IV, V, $\mathrm{VI}$ is more rare. Type III ACJ injury is described as torning of the acromioclavicular and coracoclavicular ligaments with a pronounced elevation of the distal clavicle (25-100\% widening at the coracoclavicular distance). While types I and II are typically treated conservatively, types IV and VI are often surgically treated. The management of type III injuries is still controversial (1-3). In type III AC injuries, the choice of treatment depends on
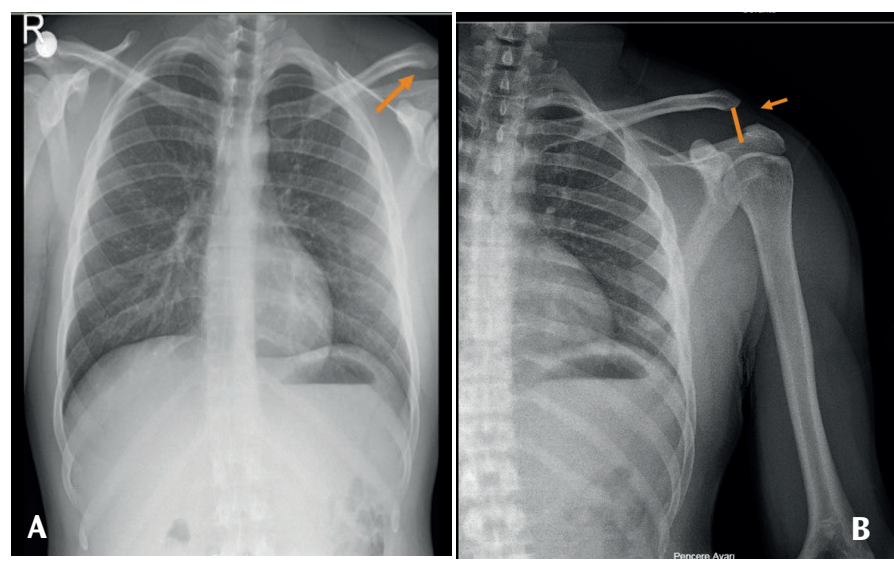

Figure 1. a,b) Type III acromioclavicular joint separation according to Rockvvood classification on left shoulder on unilateral and bilateral AP graph

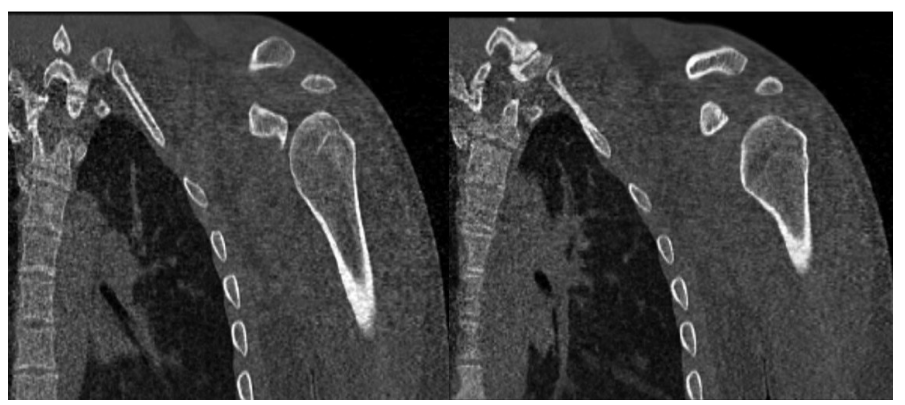

Figure 2. Acromioclavicular joint separation in the left shoulder in the captured tomography

the decision of the surgeon and the patient. Some studies prefer surgery to obtain anatomically of the shoulder good functioning in physically active young adults. Thus, chronic instability and pain will also be reduced (2-4). Some researchers prefer 

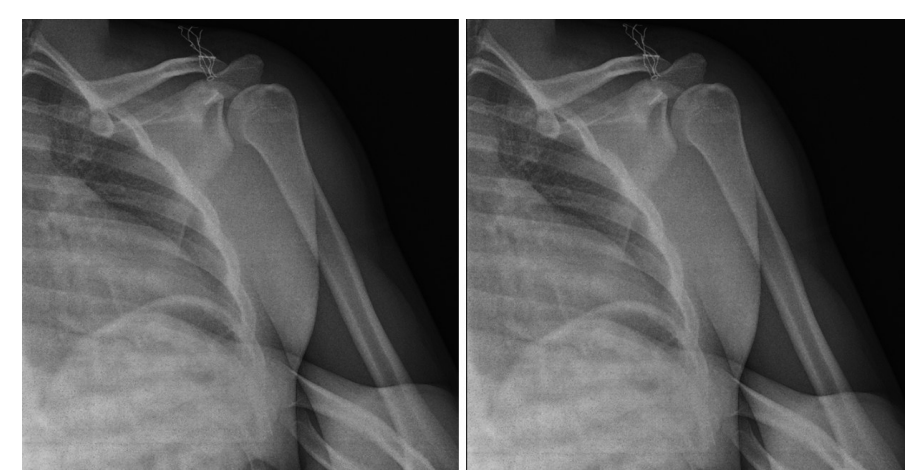

Figure 3. AP shoulder X-ray after surgery of the patient

conservative treatment especially in elderly patients due to low complication rate and duration of healing (2-5). In conclusion, most studies found no significant difference in outcomes between the operated and nonoperated groups $(2,3)$.

It is important to remember the ACJ injuries in the emergency department with severe pain in the shoulder. The patient can face cosmetic and disability consequences when such injuries are overcome. For this reason, correct classification of the injury is important and bilateral comparative radiographies may be necessary.

Keywords: Shoulder, separation, acromioclavicular joint, emergency medicine

\section{Ethics}

Ethics Committee Approval: Not required in this study.
Informed Consent: Not required in this study.

Peer-review: Externally peer-reviewed.

\section{Authorship Contributions}

Surgical and Medical Practices: A.K., S.K., G.Y., Concept: A.K., S.B., Design: A.K., S.B., Data Collection or Processing: S.K., G.Y., Analysis or Interpretation: A.K., S.B., Literature Search: A.K., Writing: A.K.

Conflict of Interest: No conflict of interest was declared by the authors.

Financial Disclosure: The authors declared that this study received no financial support.

\section{References}

1. Ibrahim EF, Forrest NP, Forester A. Bilateral weighted radiographs are required for accurate classification of acromioclavicularseparation: an observational study of 59 cases. Injury. 2015;46:1900-5

2. Smith TO, Chester R, Pearse EO, Hing CB. Operative versus non-operative management following Rockwood grade III acromioclavicular separation: a meta-analysis of the current evidence base. J Orthop Traumatol. 2011;12:1927.

3. Korsten K, Gunning AC, Leenan LPH. Operative or conservative treatment in patients with Rockwood type III acromioclavicular dislocation: a systematic review and update of current literature. Int Orthop. 2014;38:831-8.

4. Gstettner C, Tauber M, HitzI W, Resch H. Rockwood type III acromioclavicular dislocation: Surgical versus conservative treatment. J Shoulder Elbow Surg. 2008;17:220-5.

5. Calvo E, Lopez-Franco M, Arribas IM. Clinical and radiological outcomes of surgical and conservative treatment of type III acromioclavicular joint injury. J Shoulder Elbow Surg. 2006;15:300-5. 